\title{
Distribusi dan Pemetaan Varian-Varian Bahasa Bajo di Pulau Lombok
}

\author{
Ni Made Yudiastini")
}

\begin{abstract}
Abstrak
Bahasa daerah merupakan alat komunikasi intraetnik yang berfungsi sebagai penanda jati diri atau lambAng identitas pemakai bahasa yang bersangkutan. Sebagai bahasa yang hidup, bahasa daerah mempunyai kedudukan dan fungsi yang penting bagi masyarakat penuturnya dalam kegiatan kemasyarakatan atau kebudayaan. Penelitian tentang bahasa daerah perlu dilakukan mengingat pentingnya pendokumentasian pemetaan bahasa-bahasa di seluruh Indonesia. Penentuan dialek atau subdialek bahasa Bajo pun dilakukan dengan menggunakan metode dialektometri yang penekanannya pada sebaran geografis dan jumlah varian serta jumlah penutur bahasa bajo yang ada di pulau Lombok. Bahasa Bajo di pulau Lombok dapat dikelompokan menjadi dua dialek, yaitu dialek Bajo Keruat (DBK) dan dialek Bajo Tanjung (DBT).
\end{abstract}

Kata kunci: varian-varian bahasa, dialektometri dan kantong bahasa (enklave).

\section{Pengantar}

Bahasa dan manusia mempunyai hubungan yang erat. Tidak ada bahasa jika tidak ada manusia sebagai pendukungnya. Demikian juga sebaliknya. Bahasa merupakan salah satu kebudayaan yang diciptakan dan digunakan oleh manusia sendiri sebagai alat komunikasi. Oleh karena itu, bahasa harus dipelihara dan dilestarikan. Sehubungan dengan hal tersebut, bahasa Indonesia adalah bagian dari kebudayaan Indonesia. Pentingnya, kedudukan, dan fungsi bahasa daerah dalam keterkaitannya dengan pembinaan, pengembangan, dan pemantapan bahasa nasional serta kepentingan pembinaan dan pengembangan bahasa-bahasa daerah itu sendiri. Sebagai salah satu unsur, baik dalam kebudayaan daerah maupun kebudayaan nasional untuk mendapatkan perhatian dari segi pelestarian, pembinaan, dan pengembangan sebagai perwujudan garis-garis besar haluan negara di bidang kebudayaan, yang antara lain menyebutkan bahwa pengembangan nilai budaya mempunyai tujuan memperkuat kepribadian bangsa, mempertebal rasa harga diri sebagai alat kebanggaan nasional serta kesatuan nasional. Penelitian terhadap bahasabahasa daerah di Indonesia bertujuan untuk memetakan Bahasa. Sebuah peta Bahasa idealnya harus dapat merekam aktipitas berbahasa di daerah tempat Bahasa itu berasal dan juga di luar tempat terdapanya komonitas tutur bahasa tersebut. Penelitian terhadap komunitas tutur bahasa di luar tempat bahasa itu berasal atau daerah kantong bahasa perlu dilakukan karena penelitian tersebut di samping dapat mengimformasikan adanya komonitas suatu suku bangsa dan distribusi suatu daerah 
dan di suatu wilayah, dapat juga mengimformasikan tingkat mobilitas suku bangsa tersebut di luar daerah asalnya.

Penelitian ini akan mengkaji salah satu daerah kantong yang ada di pulau Lombok, khususnya di Kabupaten Lombok Timur dan Lombok Barat, yaitu daerah kantong Bahasa Bajo (BBJ):

Mengingat penelitiaan ini merupakan kajiaan variasi dialektal, maka teori yang digunakan adalah teori dialektologi, dalam hal ini teori dialektologi diakronis (periksa mahsun, 1995). Menurut teori ini, kajian dialektologi meliputi dua aspek, yaitu deskriftif dan kajian dialektologi yang didasarkan pada upaya:

a. Pendeskripsiaan perbedaan unsur-unsur kebahasaan yang terdapat dalam bahasa yang diteliti. Perbedaan itu mencakup bidang fonologi, morfologi, sintaksis, leksikon, dan semantik, termasuk pula perbedaan dari aspek sosiolinguistik;

b. Pemetaan unsur-unsur bahasa yang berbeda itu;

c. Penentuan isolek sebagai dialek atau subdialek dengan berpijak pada unsur-unsur kebahasaan yang berbeda yang telah dideskripsikan dan dipetakan;

d. Membuat deskripsi yang berkaitan dengan pengenalan dialek dan subdialek melalui pendeskripsian ciri-ciri kebahasaan yang menandai dan atau membedakan antara dialek/subdialek yg satu dengan yang lainnya.

Adapun dari aspek historis, penelitian dialektologi didasarkan pada upaya:

a. Penelusuran pengaruh antardialek/subdialek bahasa yang diteliti serta situasi persebaran geografisnya;

b. Penelusuran unsur kebahasaan yang merupakan inovasi internal ataupun eksternal dalam dialek-dialek/subdialek-subdialek bahasa yang diteliti, termasuk bahasa sumbernya (untuk inovasi eksternal) serta situasi persebaran geografisnya dalam tiap-tiap dialek atau subdialek itu;

c. Penelusuran unsur kebahasaan yang berupa unsur relik pada dialek/subdialek yang diteliti dengan situasi persebaran geografisnya.

d. Penelusuran saling hubungan antara unsur-unsur kebahasaan yang berbeda di antara dialek atau subdialek bahasa yang diteliti;

e. Membuat analisis dialek/subdialek yang inovatif dan konservatif;

f. Dalam pengertian yang terbatas, membuat rekonstruksi sejarah daerah yang bahasanya diteliti (bandingkan Mahsun, 1995 dengan Nothofer, 1987). Namun, 
patut ditambahkan bahwa tidak semua aspek historis di atas akan dibahas dalam tulisan ini, tetapi disesuaikan dengan cakupan masalah.

Sehubungan dengan itu, aspek historis yang akan dikaji hanya sampai tahap penentuan hubungan kekerabatan antarvarian bahasa Bali di pulau Lombok. Sehubungan dengan perbedaan unsur-unsur kebahasaan patut dijelaskan perbedaan konseptual antara perbedaan bidang fonologi dan leksikon. Perbedaan pada bidang fonologi ini mencakup perbedaan yang bersifat teratur atau korespondensi dan perbedaan yang bersifat sporadic (tidak teratur) atau yang disebut variasi. Termasuk ke dalam perbedaan yang bersifat teratur ini adalah apa yang disebut sebagai korespondensi sangat sempurna, sempurna, dan kurang sempurna. Perbedaan itu disebut korespondensi sangat sempurna apabila perbedaan yang disebabkan oleh perubahan bunyi itu terjadi pada semua data yang disyarati oleh kaidah perubahan serta sebaran geografisnya sama, sedangkan perbedaan yang berupa korespondensi sempurna juga terjadi pada semua data yang disyarati oleh kaidah perubahan, tetapi sebaran geografis antarcontoh yang satu dengan contoh yang lainnya tidak sama. Adapun perbedaan disebut korespondensi kurang sempurna jika perubahan bunyi itu terjadi pada $2-5$ buah contoh dengan sebaran geografis yang berbeda. Perbedaan yang berupa variasi ini dapat berupa, antara lain metatesis, asimilasi, disimilasi, apokope, sinkope, aperisis, kontraksi d1L (bandingkan Mahsun, 1995 dengan Crowley, 1987 dan Lehmann, 1973).

\section{Pembahasan}

Analisis data penelitian ini tidak dilakukan pada semua data kebahasaan yang keseluruhannya berjumlah 1080. Yang dianalisis hanya 400 kosa kata dasar, yang berisi kosa kata dasar swadesh, kosa kata budaya dasar bagian tubuh, sistem kekerabatan, gerak dan kerja dan kata tugas. Sementara data-data lain tidak dianalisis sebab analisis fonologi dan leksikon dianggap refresentatif menjawab permasalahan yang dirumuskan. Data-data lain yang tidak itu akan dijadikan data awal dalam rangka pendukung program pemetaan bahasa nasional yang diprogramkan Pusat Bahasa. Hasil analisis akan dipaparkan di bawah ini secara runtut dengan urutan perbedaan fonologi, perbedaan leksikon, dan glos-glos yang realisasinya sama.

\subsection{Deskripsi Perbedaan Linguistik dan Daerah Sebarannya}

\subsubsection{Perbedaan Fonologi}


Sebelum dilakukan pendeskripsian perbedaan fonologi, terlebih dahulu akan ditentukan prinsip-prinsip pendekatan yang digunakan. Hal ini dianggap perlu agar tidak terjadi tumpang tindih antara perbedaan fonologi dan perbedaan leksikon. Adapun prinsip-prinsip yang dimaksud adalah:

a. Perbedaan yang terdapat pada bentuk (morfem) yang menyatakan makna yang sama itu dianggap sebagai perbedaan fonologi jika perbedaan itu merupakan korespondensi. Artinya, perbedaan itu muncul secara teratur antara fonem bentukbentuk tersebut dan karenanya semua bentuk yang memperlihatkan perbedaan itu berasal dari satu etimon.

b. Apabila di samping perbedaan yang berupa korespondensi itu terdapat refleksi etimon lain yang digunakan untuk menyatakan makna tersebut, kondisi semacam ini diperlakukan sebagai perbedaan fonologi dan perbedaan leksikon.

c. Apabila perbedaan di antara bentuk-bentuk yang menyatakan makna yang sama itu berupa variasi dan perbedaan itu hanya terjadi pada satu atau dua bunyi (atau fonem) yang sama urutannya, hal itu akan dianggap sebagai perbedaan fonologi.

d. Perbedaan karena proses metatesis, desimilasi, asimilasi, kontraksi fonem, dan aferesis akan diperlakukan sebagai perbedaan fonologi, dan dikelompokkan ke dalam perbedaan yang berupa variasi

Dengan demikian, perbedaan fonologi yang dibicarakan di sini dapat dibedakan atas empat macam, yaitu: korespondensi vokal, korespondensi konsonan, variasi vokal, dan variasi konsonan.

\subsubsection{Korespondensi Vokal}

Untuk korespondensi vokal akan dikemukakan salah satu contoh dari sekitar enam buah perbedaab yang berhasil ditemukan:

1. Korespondensi antara lain: [a] [ a ] / -\# misalnya: [baka] [bake] 'dan'

Daerah sebaran korespondensi vokal ini adalah:

[a] pada daerah pengamatan 1,2

\subsubsection{Korespondensi Konsonan}

Korespondensi konsonan akan dikemukakan salah satu contoh dari empat buah perbedaan yang berhasil ditemukan.

1. Korespondensi konsonan antara [o] - [q] /-\# [uraga] - [uragaq] 'akar'.

Daerah sebaran geografis korespondensi ini adalah:

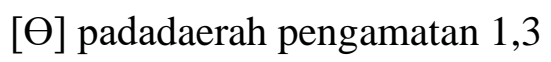


[q] pada daerah pengamatan 2

\subsubsection{Variasi Vokal}

Variasi vokal yang ditemukan berjumlah 32 buah, yang dikemukakan hanya satu sebagai contoh:

1. Variasi vokal [e-e] $-[\mathrm{e}-\mathrm{E}]$

[e-e] pada daerah pengamatan: 1

[e-E] pada daerah pengamatan: 2,3, contohnya: [kekek] - [nakEq] 'gigit'

\subsubsection{Variasi Konsonan}

Variasi konsonan yang ditemukan berjumlah 19 buah data, yang akan dikemukakan hanya satu di bawah ini:

1. Variasi Konsonan $[\Theta] \sim[\mathrm{y}] / \mathrm{v}-\mathrm{v}$

[Ө] pada daerah pengamatan: 1,3

[y] pada daerah pengamatan: 2, contohnya: [paleak] [paleyaq] 'baring'

\subsubsection{Perbedaan Leksikon}

Berdasarkan data yang diperoleh dari penelitian, ternyata perbedaan leksikon cukup banyak. Dalam penelitian ini, ditemukan tidak semuanya hanya satu contoh saja yg diharapkan dapat memberikan gambaran daerah sebaran perbedaan-perbedaan tersebut secara menyeluruh

1. Makna 'baik' memunculkan dua varian, yaitu matadda yang digunakan pada daerah pengamatan : 1, 2; malass 2 pada daerah pengamatan: 3

\subsection{Penentuan Isolek sebagai Dialek dan Subdialek}

Dalam bagian ini, akan dilakukan penentuan isolek sebagai dialek atau subdialek. Hal ini dimaksudkan agar diperoleh gambaran yang jelas mengenai hubungan yang terdapat antara isolek yang digunakan pada setiap daerah pengamatan. Untuk mencapai tujuan tersebut, upaya yang dilakukan adalah menghitung jumlah isoglos yang berfungsi menyatukan daerah-daerah pengamatan, yang menampilkan gejala kebahasaan yang serupa itu dijadikan landasan dalam menentukan isolek sebagai dialek atau subdialek. Daerah pengamatan dalam penelitian ini adalah desa Tanjung Luar, Kecamatan Keruak untuk daerah pengamatan 3, Desa Medana, Kecamatan Tanjung untuk daerah pengamatan 2, dan Desa Gili Indah, Kecamatan Pemenang untuk daerah pengamatan 1. Oleh karena 
itu, dengan menggunakan metode dialektometri, hasil yang diperoleh berupa persentase jarak unsur-unsur kebahasaan di antara tiga daerah pengamatan itu adalah sebagai berikut.

\begin{tabular}{|l|l|l|}
\hline No. & Daerah pengamatan & Persentase $(\boldsymbol{\%})$ \\
\hline 1. & $1-2$ & $38,8 \%$ \\
\hline 2. & $1-3$ & $80,1 \%$ \\
\hline 3. & $2-3$ & $80,2 \%$ \\
\hline
\end{tabular}

Selanjutnya, hasil yang diperoleh untuk menentukan hubungan antardaerah pengamatan sesuai kriteria sebagai berikut.

Daerah pengamatan 1-2 adalah dianggap beda subdialek

Daerah pengamatan 1-3 adalah dianggap beda dialek

Daerah pengamatan 2-3 adalah dianggap beda dialek

Dengan berpijak pada batasan-batasan yang dikemukakan oleh Mahsun (1995) mengenai metode penentuan dialek atau subdialek atau subdialek diatas, maka dapatlah dikatakan Bahasa Bajo (BBJ) memiliki dua dialek yaitu:

1. Dialek Bajo Keruak yang mencakup daerah pengamatan 3

2. Dialek Bajo Tanjung yang mencakup daerah pengamatan 1 dan 2

Penentuan dialek-dialek di atas didasarkan pada persentase yang dihasilkan melalui analisis dialektometri. Dari perhitungan ini, dapat dilihat bahwa dari 121 buah peta yang diperbandingkan antara daerah pengamatan 1 dan 2, terdapat 47 buah peta yang berbeda di antara keduanya . ini artinya, hanya terdapat $38,8 \%$ yang berbeda sehingga kedua daerah pengamatan tersebut dinyatakan sebagai perbedaan subdialek. Dengan demikian, keduanya dapat dimasukkan ke dalam satu dialek karena subdialek merupakan bagian dari dialek yang dapat dinamakan dengan Dialek Bajo Tanjung (DBT). Apabila kedua daerah pengamatan yang tergabung dalam DBT itu dibandingkan dengan daerah pengamatan 3, yakni baik dengan daerah pengamatan 1 maupun 2, masing-masing terdapat 98 dan 97 buah buah peta yang berbeda. Ini berarti terdapat $80,1 \%$ dan $80,2 \%$ yang beda sehingga dapat dikatan antara daerah pengamatan 1 dan 2 dengan daerah pengamatan 3 yang dibandingkan merupakan perbedaan dialek dengan kata lain daerah pengamatan 3 merupakan dialek tersendiri dengan dialek yang menyatukan antara daerah pengamatan 1 dan 2 (DBT), sedangkan untuk daerah pengamatan 3 kita sebut dialek Bajo Keruak (DBK). 


\section{Peta Bahasa dan Dialek-Dialek Bahasa Bajo}

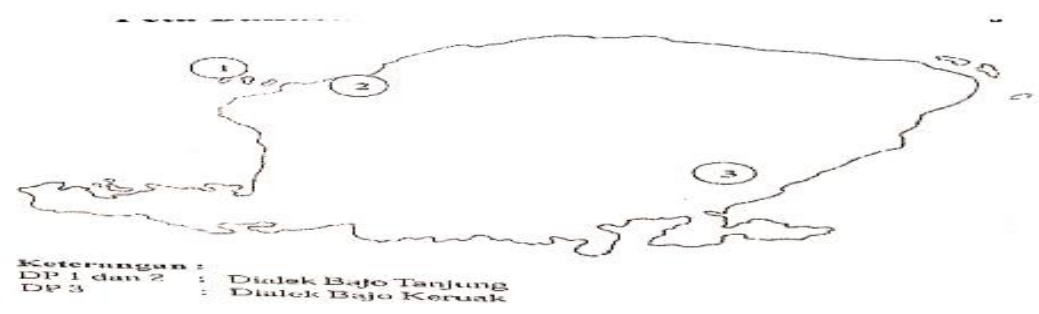

Keterangan

DP 1 dan 2 : Dialek Bajo Tanjung

DP 3 : Dialek Bajo Keruak

\section{Simpulan}

Dari penelitian yang dilakukan terhadap Bahasa Bajo di pulau Lombok dengan menggunakan pendekatan dialektologis, telah diperoleh 121 buah peta perbedaan unsur-unsur kebahasaan (fonologi dan leksikon), yang dikumpulkan pada 3 buah daerah pengamatan. Pembahasan terhadap 121 buah peta tersebut dilakukan secara sinkronis, pengelompokan daerah-daerah pengamatan yang bertetangga ke dalam dialek atau subdialek didasarkan pada analisis pemahaman timbal balik, dialektometri, dan berkas isoglos. Berdasarkan analisis tersebut, terungkap bahwa bahasa bajo di pulau Lombok terbagi ke dalam dua dialek, yaitu Dialek Bajo Tanjung (DBT) dan Dialek Bajo Keruak (DBK). Secara diakrononis, tingkat kedekatan antara dialek-dialek antara DBT dan DBK memiliki perbedaan. Dengan demikian, dapat dikatakan bahwa pada faktor historis, penyebaran DBK lebih dahulu daripada DBT. 
Mabasan, Vol. 1, No. 2, Juli-Desember 2007: 40-48 


\section{DAFTAR PUSTAKA}

Burhanuddin, dkk. 2005. Kontak Bahasa Antara Bahasa Sumbawa Dengan Bahasa Sasak di Lombok Timur. Mataram: Kantor Bahasa Provinsi Nusa Tenggara Barat.

Bloomfield, Leonard. 1995. Bahasa (Language). Jakarta: Gramedia Pustaka Utama.

Chaer, Abdul dan Leoni Agustina. 1995. Sosiolinguistik: Suatu Pengantar. Jakarta: Rineka Cipta

Foley, Wiliam A. 1997. Anthrpolgical Linguistik: An Introduction. Malden, USA: Blackwell Publishers Inc.

Husnan, Lalu Erwan, 2003 “Alih Kode pada Masyarakat Penutur Bahasa Bajo di Pulau Maringgik Lombok Timur.

Mahsun. 1995. Dialektologi Diakronis: Sebuah Pengantar Yogyakarta: Gajah Mada University Prees.

Mahsun. 2005. Metode Penelitian Bahasa: Tahapan Strategi, Metode dan Tekniknya. Jakarta: PT Raja Grafindo Persada.

Mahsun, 2006. Bahasa Relasi Sosial: Telah Kesepadan Adaptasi Linguistik dengan Adaptasi Sosial. Yogyakarta: Gama Media.

Soekanto, Soerjono. 2005. Sosiologi Suatu Pengantar. Jakarta: Raja Grafindo Persada.

Sumarsono. 2002. Sosiolinguistik. Yogyakarta: Sabda.

Sudika, Inyoman. 1998. Isolek Bali di Lombok: Kajian Dialektologi dan Diakronis. Denpasar: Tesis S-2 Universitas Udayana. 